\title{
Coseismic effects recorded by Fujian subsurface fluid network and its meaning to earthquake prediction*
}

\author{
Lixia Liao ^ Xiaoyin Ni Meiling Wang and Shaozu Wu \\ Earthquake Administration of Fujian Province, Fuzhou 350003, China
}

\begin{abstract}
Based on analyses of the spatio-temporal evolutionary characteristics of teleseismic response recorded by Fujian subsurface fluid network and in combination with earthquakes happened in Fujian province during the same period, this paper points out that the step-like rising of water level after distant earthquakes may include some regional stress field information, and the area where water level step-like rises could be the position that the stress concentrated on and where the future earthquakes would occur. If combined with other impending precursors, the location of the events may be predicted to a certain degree.
\end{abstract}

Key words: Fujian subsurface fluid network; well water level; coseismic effect; spatio-temporal evolutionary characteristic; water level oscillation

CLC number: P315.72 3 Document code: A

\section{Introduction}

The tremendous earthquakes happened frequently since 2004, from which we got a great deal of experiences in teleseismic response and post-seismic response recorded by the subsurface fluid observation network. Taking the teleseismic response acquired by the well water level of Fujian subsurface fluid network in recent years for an example, this paper mainly studies the teleseismic effect caused by the Nantou, Taiwan province, earthquake with $M_{\mathrm{S}} 7.6$ on 21 September 1999 and the Sumatra $M_{\mathrm{S}} 8.7$ earthquake on 26 December 2004. The other earthquakes are also analyzed.

Since the water level oscillation was observed in the well Wali, Beijing (Cai, 1980) in 1970's, which is a phenomenon of water level change due to microdynamics, it has been observed in more and more wells in China (Wang et al, 1998). The water level oscillation was recognized more and more widely, and its application has become increasingly important. Not only there is better cognition of earthquake recording abilities and influence factors (Che et al, 1989; Che, 1990; Che and Yu, 1992; Zhang et al, 1999a, b, 2000; Chen and Liu,

\footnotetext{
* Received 7 July 2008; accepted in revised form 2 November 2008; published 10 June 2009.

• Corresponding author. e-mail: redllx@tom.com
}

2006), but also water level oscillation could be used to analyze the spatio-temporal evolution of large-scale stress field in China, since water level oscillation indicates the stress state of aquifer in borehole (Zhang et al, 1994). Some explorations were made on calculating the magnitude of huge earthquakes around the world; at the same time the researches were done on the relationship between the earthquake recording ability of well water level and large earthquakes (Wan, 1992).

After the 1976 Tangshan great earthquake some scholars set about study on the relationship between coseismic anomalies and future earthquakes (Editorial Board of Tangshan Earthquake in 1976, State Seismological Bureau, 1982). At that time, however, the large-scale coseismic and post-seismic effects have not been recorded due to small-scale subsurface fluid network, low observing ability and few subsequent stronger quakes, therefore the relevant literatures were very few. Until the Nantou, Taiwan, $M_{\mathrm{S}} 7.6$ earthquake happened on 21 September 1999, subsurface water level fluctuation and step-like anomalies were extensively recorded in southwestern, southern, eastern, and northern China. Huang et al (2000) pointed out that the spatial clustering area of the responding anomalies is of indicative significance on predicting the location of future earthquakes. Coseismic and post-seismic response caused by 
the Sumatra earthquakes with $M_{\mathrm{S}} 8.7$ on 26 December 2004, and with $M_{\mathrm{S}} 8.5$ on 29 March 2005 affected a wide area in China, but researchists paid more attention to collection and statistics of the water level response (Department of Monitoring and Prediction, China Earthquake Administration, 2005), analyses on earthquake recording ability (Gao et al, 2006), and researches on the responding characteristics ( $\mathrm{Fu}$ et al, 2007; Liao and Wang, 2008). Liao et al (2006) analyzed the post-seismic response of fluids in China caused by the 2004 and 2005 Sumatra huge earthquakes, and stated that the water level step-like rising/declining caused by the quakes might have indicative signification on subsequent earthquakes in Chinese mainland in the Sixth International Symposium on Tianshan Earthquakes in 2006.

\section{Spatio-temporal distribution charac- teristics of coseismic response of water level recorded by Fujian subsurface fluid network}

\subsection{Water level observation wells of Fujian subsur- face fluid network}

There were 29 water level observation wells used for routine analyses, 28 of which provide digital data, and the other one well, Yong'an, provides analogous records. These wells mostly distribute at NE- and NW-trending structural fault zones in Fujian province
(Figures 1 and 2). Most of them are bore holes with well depth between $100 \mathrm{~m}$ and $150 \mathrm{~m}$, and a few of them exceed $200 \mathrm{~m}$ in deep. Well Yong'an is the deepest of 1000 $\mathrm{m}$, and the shallowest is well Youxi, only $63 \mathrm{~m}$ deep. Dynamic water levels are recorded at well Yongchun No.1 and Minqing; static water levels are recorded at other wells. Water lithologic observation focuses on granite series. The main water level observation wells are listed in Table 1.

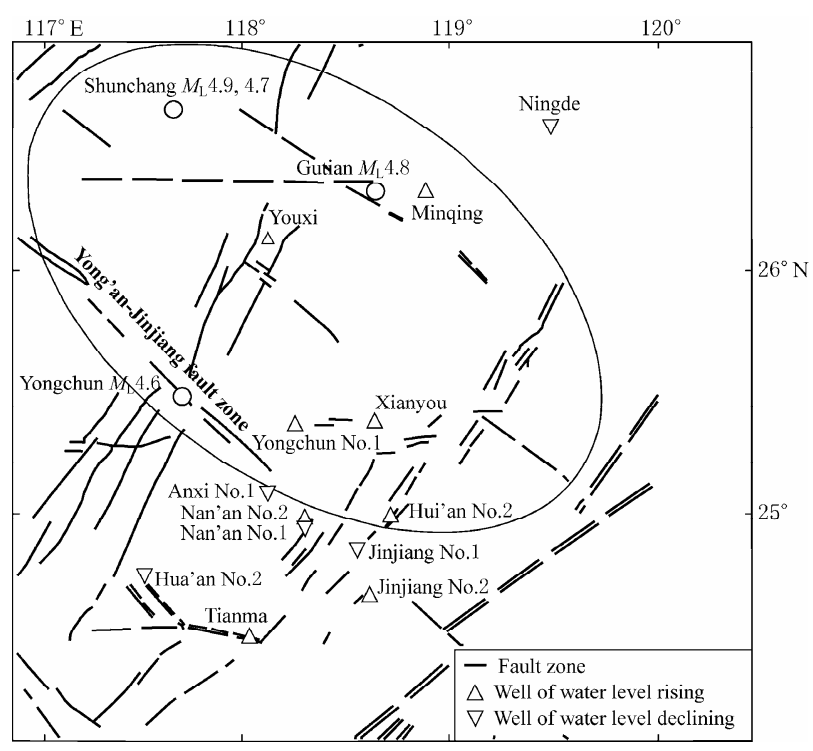

Figure 1 Fujian subsurface fluid network and its teleseismic response to the Sumatra $M_{\mathrm{S}} 8.7$ earthquake in 2004.

Table 1 General situation of main water level wells of Fujian subsurface fluid network

\begin{tabular}{|c|c|c|c|c|c|c|c|}
\hline Name of well & Depth/m & Observation type & Lithology of aquifer & Name of well & Depth/m & Observation type & Lithology of aquifer \\
\hline Quanzhouju & 130.00 & Static & Monzonitic granite & Xianyou & 103.49 & Static & Lava \\
\hline Yongchun No.1 & 5.00 & Dynamic & Granite & Youxi & 63.00 & Static & Sandstone \\
\hline Anxi No.1 & 102.20 & Static & Granite & Yong'an & 1000.44 & Static & Tuff lava \\
\hline Jinjiang No.1 & 100.38 & Static & Monzonitic granite & Ningde & 63.00 & Static & Prophyritic granite \\
\hline Jinjiang No.2 & 202.72 & Static & Biotite granite & Minhou & 110.69 & Static & Tuff lava \\
\hline Nan'an No.1 & 120.91 & Static & Glassy tuff crumbs & Minqing & 100.12 & Dynamic & Granite \\
\hline Nan'an No.2 & 150.00 & Static & Glassy tuff crumbs & Pudong & 201.76 & Static & Granite \\
\hline Hui'an No.1 & 100.25 & Static & Granodiorite & Pingtan & 255.87 & Static & Granite \\
\hline Hui'an No.2 & 150.63 & Static & Granodiorite & Changle & 100.40 & Static & Granite \\
\hline Hua'an No.2 & 146.37 & Static & Crystal chip lava & Lianjiang & 100.30 & Static & Granite \\
\hline Nanjing & 102.44 & Static & Granodiorite & Luoyuan & 106.80 & Static & Granite \\
\hline Tianma & 103.00 & Static & Granite & Shishi & 130.31 & Static & Granite \\
\hline
\end{tabular}

\subsection{Selection of earthquake events}

The Sumatra earthquake with $M_{\mathrm{S}} 8.7$ in 2004 was chosen to study teleseismic response recorded by water levels because the water level step-like rising/declining and water level oscillation led by this event has been the largest-scale co-seismic effect since Fujian fluid network operated in 2004. For the huge earthquake affected widely, different types of co-seismic responses were recorded by many wells. So this paper selects the $M_{\mathrm{S}} 8$ events around the world since 2004 for study. Considering that Taiwan lies adjacent to Fujian, the $M_{\mathrm{S}} 7$ earthquakes will have influence on Fujian, so the $M_{\mathrm{S}}>7$ earthquakes in Taiwan and $M_{\mathrm{L}}>4.5$ in Fujian are included in the analysis. As listed in Table 2, 11 earthquakes are chosen in the end. 


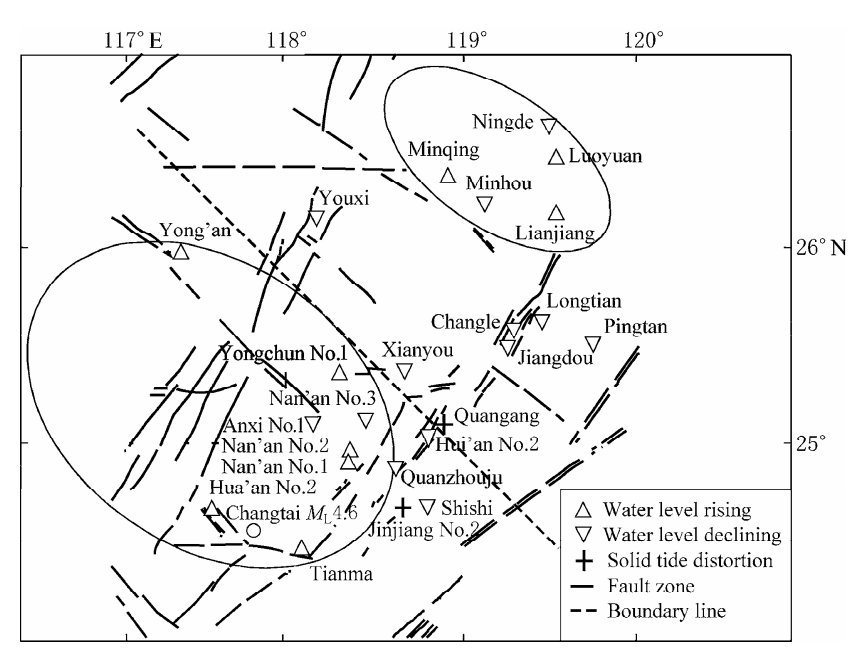

Figure 2 Spatial distribution of teleseismic response of Fujian subsurface fluid network to the 2008 Wenchuan $M_{\mathrm{S}} 8.0$ earthquake.

Table 2 Earthquake events used in this paper

\begin{tabular}{cclc}
\hline No. & $\begin{array}{c}\text { Date } \\
\text { a-mo-d }\end{array}$ & Earthquake location & $M_{\mathrm{S}}$ \\
\hline 1 & $2004-12-26$ & Northwest offshore of Sumatra, Indonesia & 8.7 \\
2 & $2005-03-29$ & North of Sumatra, Indonesia & 8.5 \\
3 & $2006-04-21$ & Northeast of Kamchatka peninsula & 8.0 \\
4 & $2006-11-15$ & Kuril islands & 8.0 \\
5 & $2006-12-26$ & Southern sea of Taiwan & 7.2 \\
6 & $2007-03-13$ & Shunchang of Fujian province & $4.9\left(M_{\mathrm{L}}\right)$ \\
7 & $2007-08-29$ & Yongchun of Fujian province & $4.6\left(M_{\mathrm{L}}\right)$ \\
8 & $2007-09-12$ & Southern sea of Sumatra, Indonesia & 8.5 \\
9 & $2007-09-13$ & Southern sea of Sumatra, Indonesia & 8.3 \\
10 & $2008-03-06$ & Gutian of Fujian province & $4.8\left(M_{\mathrm{L}}\right)$ \\
11 & $2008-05-12$ & Wenchuan of Sichuan province & 8.0 \\
\hline
\end{tabular}

\subsection{Spatio-temporal distributing characteristics of teleseismic responses}

The earthquake-recording ability of Fujian subsurface fluid network is high, and many huge earthquakes in world and moderately strong earthquakes in Fujian and Taiwan took place was recorded. After analyzing co-seismic and post-seismic responses of Fujian well water level caused by the 11 earthquake events above mentioned, it is shown that the responses such as water level step-like rising/declining of each well to different quakes were not invariable, and exhibited clustering characteristic in the spatial distribution, which was divided by a tectonic zone sometimes. For instance, after the Sumatra, Indonesia, $M_{\mathrm{S}} 8.7$ earthquake on 26 December 2004, it is represented by Fujian fluid network that the water levels at most wells in NE side show step-like rising and at most wells in SW side show step-like declining with Yong'an-Jinjiang fault zone as boundary (Figure 1). After the Wenchuan, Sichuan, $M_{\mathrm{S}} 8.0$ earthquake on 12 May 2008, the wells with step-like rising water-level concentrated on the areas such as Yong'an, Zhangzhou, Xiamen and Shuikou reservoir. In addition, water level at the wells in NE side is registered as step-like declining and that at the wells in SW side as step-like rising bounded by an adelomorphic boundary parallel to the Yong'an-Jinjiang fault zone (Figure 2).

We also found, each well has different response to different earthquakes in time. Their morphological growth registered as changing dynamically with time, but the variation had a relatively steady period, i.e., step-like rising and declining both would last some time, not switch to each other frequently, and when the switching runs, variation of water levels would be in synchronism for many wells. For example, wells Youxi, Minhou and Hui'an No.2 registered as water level step-like rising or water level oscillation in the earthquakes before 2008, but they all switched to decline at the same time when the Wenchuan, Sichuan, $M_{\mathrm{S}} 8.0$ earthquake happened on May 12, 2008. Well Nan'an No.1 registered as step-like rising when the Sumatra $M_{\mathrm{S}} 8.7$ earthquake occurred on December 26, 2004, but it also switched to step-like rising on May 12, 2008. As for well Yongchun No.1, water level registered as rising to most quake events, yet when Kuril islands $M_{\mathrm{S}} 8.0$ earthquake happened, it registered as water level oscillation, and no response to Gutian $M_{\mathrm{L}} 4.8$ earthquake. Well Anxi No.1 registered as declining to most of earthquakes and as solid tide distortion in other cases; well Xianyou registered as rising when Sumatra earthquake with $M_{\mathrm{S}} 8.7$ happened on December 26, 2004, yet registered as water level oscillation when southern sea of Sumatra $M_{\mathrm{S}} 8.5$ and $M_{\mathrm{S}} 8.3$ quakes happened, and declining was observed at well Xianyou when Wenchuan earthquake happened (Figure 3). Figure 4 shows typical water level step-like rising/declining dynamic curve, and the coseismic response varying with time is listed in Table 3.

\section{Relationship between the spatio- temporal distributing characteristics of co-seismic response and seismic activi- ties in Fujian region}

Tracking the spatio-temporal evolution of co-seismic response of Fujian subsurface fluid network, we found, whether on the space or on the time, that there is a relatively steady clustering area of water level step-like rising in a longer time span (ellipse area in Figure 1). Three bitches of $M_{\mathrm{L}}>4.5$ earthquakes, i.e., Shunchang $M_{\mathrm{L}} 4.9$ 
and $M_{\mathrm{L}} 4.7$, Yongchun $M_{\mathrm{L}} 4.6$, Gutian $M_{\mathrm{L}} 4.8$, happened in $M_{\mathrm{S}} 8.0$ earthquake, this relatively steady clustering area this clustering area since 2007. After the Wenchuan
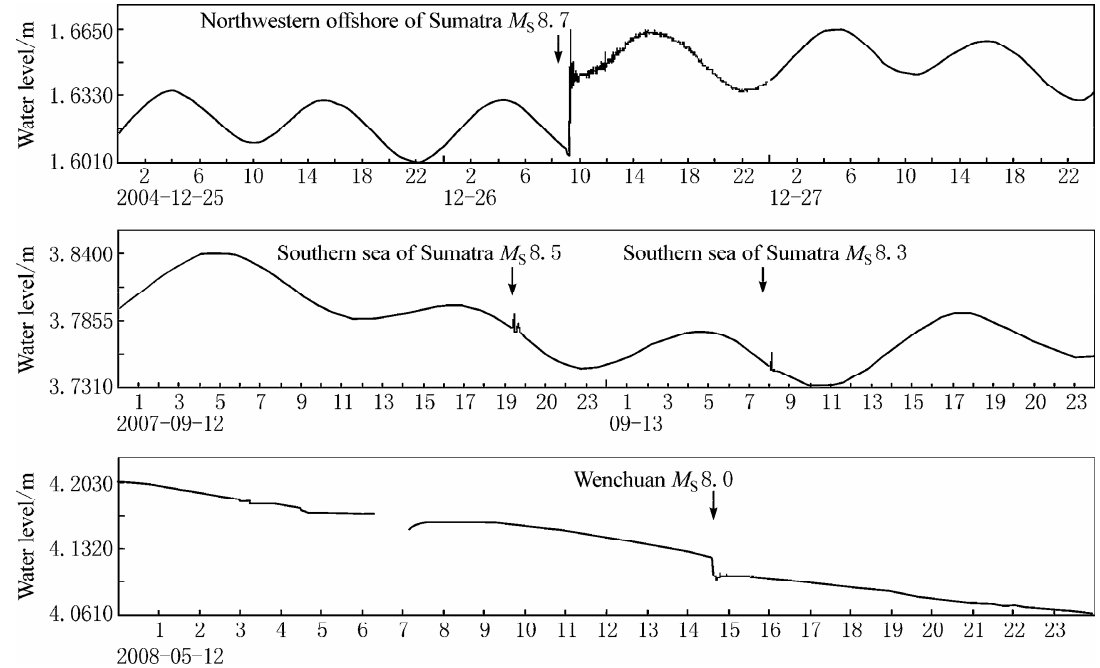

Figure 3 Teleseismic response of water level of well Xianyou to different earthquakes.
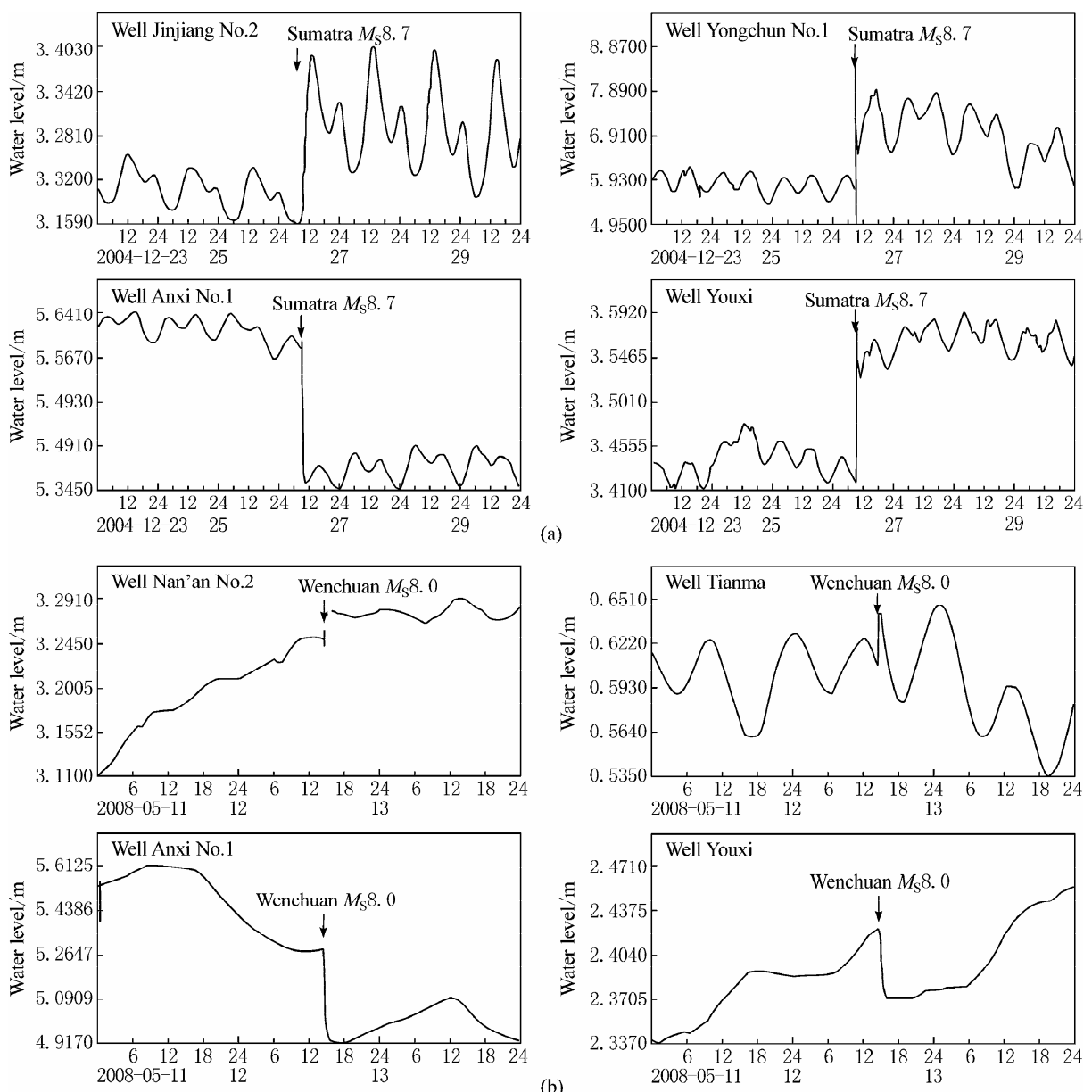

Figure 4 Typical dynamic curve of the step-like rising/declining of water level responding to the Sumatra $M_{\mathrm{S}} 8.7$ (a) and Wenchuan $M_{\mathrm{S}} 8.0$ earthquakes (b), respectively. 
Table 3 Evolution of coseismic response of Fujian water level network

\begin{tabular}{|c|c|c|c|c|c|c|c|c|c|c|c|c|c|c|c|c|c|c|c|c|c|c|c|c|c|}
\hline \multicolumn{3}{|c|}{ Earthquake } & \multicolumn{23}{|c|}{ Coseismic response of water level } \\
\hline $\begin{array}{c}\text { Date } \\
\text { a-mo-d }\end{array}$ & Location & $M_{\mathrm{S}}$ & 1 & 2 & 3 & 4 & 5 & 6 & 7 & 8 & 9 & 10 & 11 & 12 & 13 & 14 & 15 & 16 & 17 & 18 & 19 & 20 & 21 & 22 & 23 \\
\hline $2004-12-26$ & Sumatra & 8.7 & $\uparrow$ & $\uparrow$ & $\downarrow$ & $\uparrow$ & $\downarrow$ & $\uparrow$ & $\uparrow$ & $\uparrow$ & $\uparrow$ & $\downarrow$ & & & & $\downarrow$ & $\uparrow$ & $\downarrow$ & $\downarrow$ & $\uparrow$ & & & & & \\
\hline 2005-03-29 & Sumatra & 8.5 & $\uparrow$ & $\rightarrow$ & $\uparrow$ & $\uparrow$ & $\downarrow$ & $\uparrow$ & $\rightarrow$ & $\uparrow$ & $\rightarrow$ & & & & & $\downarrow$ & $\rightarrow$ & $\uparrow$ & & & & & & & \\
\hline 2006-04-21 & Kamchatka & 8.0 & $\uparrow$ & $\rightarrow$ & $\rightarrow$ & $\uparrow$ & & $\rightarrow$ & $\rightarrow$ & & & & & & & & & $\downarrow$ & & & & & & & \\
\hline $2006-11-15$ & Kuril islands & 8.0 & $\rightarrow$ & $\rightarrow$ & & $\uparrow$ & $\downarrow$ & $\rightarrow$ & $\rightarrow$ & & & & & & $\uparrow$ & & & & & & & & & & \\
\hline $2006-12-26$ & Southern Taiwan & 7.2 & $\uparrow$ & $\rightarrow$ & $\downarrow$ & $\uparrow$ & * & $\rightarrow$ & $*$ & & & & $\downarrow$ & & $\rightarrow$ & & & $\uparrow$ & & & $\downarrow$ & $\uparrow$ & & & \\
\hline $2007-03-13$ & $\begin{array}{l}\text { Shunchang, } \\
\text { Fujian }\end{array}$ & $4.9\left(M_{\mathrm{L}}\right)$ & $\uparrow$ & $\rightarrow$ & & $\uparrow$ & $\downarrow$ & & & & & & & & & & & & & & & & & & \\
\hline 2007-08-29 & Yongchun, Fujian & $4.6\left(M_{\mathrm{L}}\right)$ & $\uparrow$ & & & $\uparrow$ & & & & $\uparrow$ & & & & & & & & & & & & & & & \\
\hline 2007-09-12 & Sumatra & 8.5 & $\uparrow$ & $\rightarrow$ & $\downarrow$ & $\uparrow$ & $\downarrow$ & $\rightarrow$ & $\rightarrow$ & $\uparrow$ & $\rightarrow$ & & $\rightarrow$ & $\rightarrow$ & $\uparrow$ & $\rightarrow$ & * & $\uparrow$ & & & $\downarrow$ & $\uparrow$ & $\uparrow$ & & \\
\hline 2007-09-13 & Sumatra & 8.3 & $\uparrow$ & $\rightarrow$ & $\rightarrow$ & & $\rightarrow$ & $\uparrow$ & $\rightarrow$ & $\uparrow$ & $\rightarrow$ & & $\rightarrow$ & $\rightarrow$ & $\rightarrow$ & $\rightarrow$ & $\rightarrow$ & $\uparrow$ & & & & & & & \\
\hline 2008-03-06 & Gutian, Fujian & $4.8\left(M_{\mathrm{L}}\right)$ & & & & & $*$ & & & & & & & $\uparrow$ & & & & & & & & & & & \\
\hline $2008-05-12$ & $\begin{array}{l}\text { Wenchuan, } \\
\text { Sichuan }\end{array}$ & 8.0 & $\uparrow$ & $\uparrow$ & & $\downarrow$ & $\downarrow$ & $\downarrow$ & $\downarrow$ & $\uparrow$ & $\downarrow$ & $\uparrow$ & $\downarrow$ & $\uparrow$ & $\uparrow$ & $\downarrow$ & $\uparrow$ & $\uparrow$ & & $*$ & $\downarrow$ & $\downarrow$ & $\downarrow$ & $\uparrow$ & $\downarrow$ \\
\hline
\end{tabular}

Note: The numbers 1 to 23 denote the well of Yongchun No.1, Yong'an, Nanjing, Youxi, Anxi No.1, Minhou, Xianyou, Nan'an No.2, Hui'an No.2, Nan'an No.1, Quanzhouju, Minqing, Lianjiang, Ningde, Tianma, Hua'an No.2, Jinjiang No.1, Jinjiang No.2, Pudong, Pingtan, Changle, Luoyuan, Shishi, respectively. $\uparrow, \downarrow, \rightarrow, *$, and blank denote water level step-like rising and declining, water level oscillation, earth tide distortion and no co-eismic effect, respectively.

rising, a larger one in Yong'an, Zhangzhou, Xiamen, the other in Shuikou reservoir (as shown by ellipses in Figure 2). At the 2008 midyear consultation the authors proposed that there would be a moderately strong earthquake in the Yong'an-Zhangzhou-Xiamen ellipse area on the basis of above analyses, and a $M_{\mathrm{L}}<4$ earthquake would happen in the area of Shuikou reservoir in the second half year. As a result, the Changtai $M_{\mathrm{L}} 4.7$ earthquake happened just in the larger ellipse area on July 5, 2008 (Figure 2), and on the same day a $M_{\mathrm{L}} 3.8$ quake happened in the area of Shuikou reservoir. The two earthquakes happened only 54 days away from the Wenchuan earthquake, and the occurrence location transferred to the new centralizing area of step-like rising from the old one. Above examples demonstrate that the centralizing area of water level step-like rising maybe the place of future earthquake occurrence.

The average velocity of crustal block observed by GPS also reveals that there was a NW-trending boundary in the vicinity of Yongchun, and the stations in the two sides of the boundary record the movement of crustal block toward opposite direction (Figure 5), which is inosculated with the boundary divided by water level step-like rising/declining after the Wenchuan earthquake. So, centralizing area of water level step-like rising is very likely to be the stress-centralized area resulted from regional compression. And Xianyou water level co-seismic response registered as step-like rising when the Sumatra $M_{\mathrm{S}} 8.7$ quake happened on 26 December 24 , and the water level oscillation appeared when Sumatra $M_{\mathrm{S}} 8.5$ and $M_{\mathrm{S}} 8.3$ quakes happened on September 12, 13, 2007. When Wenchuan $M_{\mathrm{S}} 8.0$ earthquake happened, it shows water level declining. This is

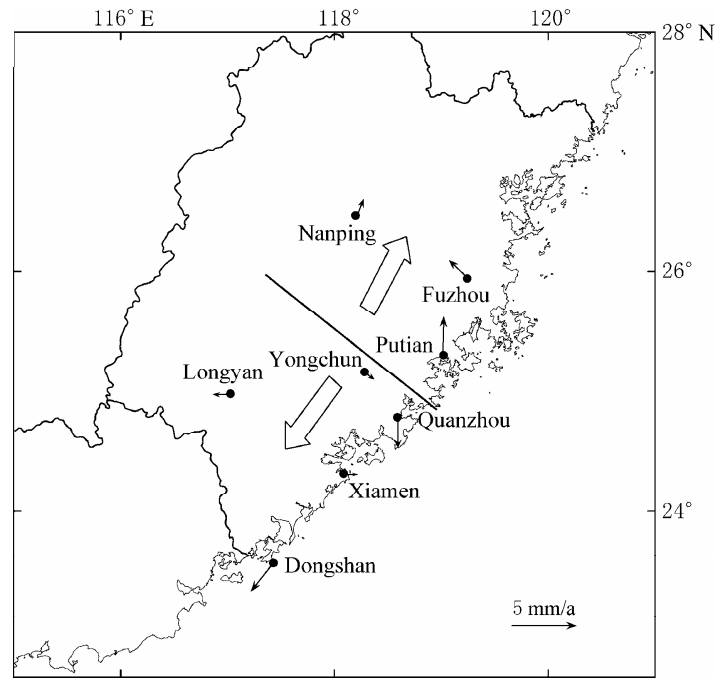

Figure 5 Average velocity sketch of the stations observed by Fujian GPS network.

most likely a process that regional stress switched from compression to a balance and then to the tensile state.

The lasting time and amplitude of the coseismic effect also show some relationship with seismicities. Take well Yongchun No.1 for an example, after the Shunchang $M_{\mathrm{L}} 4.9$ earthquake, water level rising at well Yongchun lasted four days with altitude reaching $1.99 \mathrm{~m}$; but it just $0.93 \mathrm{~m}$ after the subsequent Yongchun $M_{\mathrm{L}} 4.6$ earthquake and lasted less than two days; after the Wenchuan $M_{\mathrm{S}} 8.0$ it reached a high level but only lasted one day and began to decline. The authors think that the rising amplitude is determined by regional stress and outside force; whereas the lasting time is mainly determined by regional stress. The regional stress during the 
impending period of the earthquake preparation is stronger than normal, and the instantaneous force during earthquake, even a small earthquake, could lead to higher raising amplitude of water level and longer lasting time. The Wenchuan $M_{\mathrm{S}} 8.0$ earthquake had a high magnitude, and the instantaneous force was very strong, so the rising amplitude of water level was very high. Yet it experienced the Yongchun earthquake, the regional stress had released to an extent, thus the water level did not rise and just lasted one day (Table 4 and Figure 6).
Table 4 Teleseismic response of water level at well Yongchun to different earthquakes

\begin{tabular}{clccc}
\hline & Earthquake & & $\begin{array}{c}\text { Postseismic } \\
\text { increasing } \\
\text { amplitude of } \\
\text { water level/m }\end{array}$ & $\begin{array}{c}\text { Rising time of } \\
\text { postseismic } \\
\text { water level/d }\end{array}$ \\
\hline $\begin{array}{c}\text { Date } \\
\text { a-mo-d }\end{array}$ & Location & $M_{\mathrm{S}}$ & 1.14 & 1 \\
\hline $2006-12-26$ & $\begin{array}{l}\text { Southern sea } \\
\text { of Taiwan }\end{array}$ & 7.2 & & 4 \\
$2007-03-13$ & Shunchang & $4.9\left(M_{\mathrm{L}}\right)$ & 1.99 & 2 \\
$2007-08-29$ & Yongchun & $4.6\left(M_{\mathrm{L}}\right)$ & 0.93 & 1 \\
$2007-09-12$ & Sumatra & 8.5 & 0.65 & 1 \\
$2007-09-13$ & Sumatra & 8.3 & 2.32 & 2 \\
$2008-05-12$ & Wenchuan & 8.0 & & \\
\hline
\end{tabular}
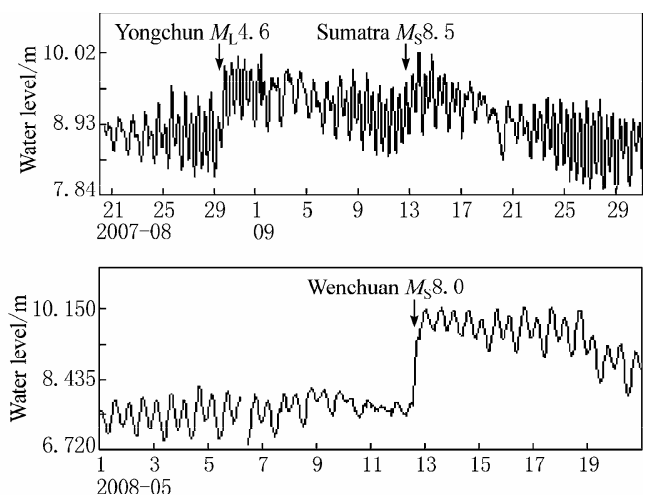

Figure 6 Teleseismic response of water level in well Yongchun to several earthquakes.

\section{Relationship between earthquakes and teleseismic response}

The coseismic effect in Chinese mainland caused by Taiwan $M_{\mathrm{S}} 7.6$ on September 211999 was evident; the regional large-scale water level step-rise effects were observed in China during the earthquake. Based on the analyses on this event, we found that the earthquakes took place almost in the areas where water level step-like rising focused several months later. For example, the coseismic effects were found at 12 stations in Liaoning province, among which the water level step-rising was observed at 11 stations; soon after the Haicheng-Xiuyan earthquake swarm with maximum magnitude $M_{\mathrm{S}} 5.4$ occurred during November of 1999 to January of 2000. The coseismic effects and water level step-like rising were found at four stations in the boundary area between Sichuan and Yunnan, where the Yao'an earthquake of $M_{\mathrm{S}} 6.5$ occurred in January of 2000 . The coseismic effect was found at six stations in Shanxi and Hebei

Table 5 Teleseismic response of China water level network to the Nantou $M_{\mathrm{S}} 7.6$ earthquake

\begin{tabular}{|c|c|c|c|c|}
\hline Location & Well of water level step-like rising & $\begin{array}{l}\text { Well of water level } \\
\text { step-like declining }\end{array}$ & $\begin{array}{l}\text { Well showing water level } \\
\text { oscillation }\end{array}$ & Subsequent earthquakes \\
\hline $\begin{array}{l}\text { Liaoning } \\
\text { province }\end{array}$ & $\begin{array}{l}\text { Loufang, Tangchi, Zhoujia, Benxi No.1, } \\
\text { Ming'an, Shuidonggou, Shanlongyu, } \\
\text { Biandian, Liguan, Xiuyan No.1, Xiuyan No.2 }\end{array}$ & Qiyi & & $\begin{array}{l}\text { Haicheng-Xiuyan } M_{\mathrm{S}} 5.4 \text { earth- } \\
\text { quake swarm during November } \\
\text { of } 1999 \text { to January of } 2000\end{array}$ \\
\hline $\begin{array}{l}\text { Junction of } \\
\text { Sichuan-Yunnan }\end{array}$ & $\begin{array}{l}\text { Simian and Huili in Sichuan province, } \\
\text { Kunming and Eryuan in Yunnan province }\end{array}$ & & & $\begin{array}{l}\text { Yao'an } M_{\mathrm{S}} 6.5 \text { earthquake in } \\
\text { January of } 2000\end{array}$ \\
\hline $\begin{array}{l}\text { Hebei and } \\
\text { Shanxi } \\
\text { provinces }\end{array}$ & $\begin{array}{l}\text { Wanquan and Changli in Hebei province, } \\
\text { Wuliying in Beijing, Xiaoyi in Shanxi } \\
\text { province, Sanyuan in Shaanxi province }\end{array}$ & & Taipingzhuang in Beijing & $\begin{array}{l}\text { Datong } M_{\mathrm{S}} 5.6 \text { earthquake in } \\
\text { November of } 1999\end{array}$ \\
\hline $\begin{array}{l}\text { Guangdong and } \\
\text { Guangxi } \\
\text { provinces }\end{array}$ & Zhukeng in Guangdong province & & $\begin{array}{l}\text { Jiutang, Hesan, Qinzhou } \\
\text { and Beihai in Guangxi } \\
\text { province }\end{array}$ & No \\
\hline Jiangsu province & $\begin{array}{l}\text { Jurong No. } 16 \text {, Zhenjiang No. } 17 \text {, } \\
\text { Suzhou No. } 20\end{array}$ & Kunshan No. 21 & $\begin{array}{l}\text { Xuzhou No.2, Xuzhou No.3, } \\
\text { Suqian No.5, Huaiyin No.6, } \\
\text { Zhenjiang No.18 }\end{array}$ & No \\
\hline
\end{tabular}


provinces, the water level step-like rising were found at five wells of this region, where the Datong earthquake of $M_{\mathrm{S}} 5.6$ occurred in November of 1999. No teleseismic responses were found in Jiangsu province, and no earthquake occurred in these provinces (Table 5, Huang et al, 2000). The coseismic effects and water level step-like rising were found in Yunnan province during the Sumatra $M_{\mathrm{S}} 8.7$ on 26 December 2004, Simao $M_{\mathrm{S}} 5.0$ earthquake on 26 January 2005 , Huize $M_{\mathrm{S}} 5.3$ earthquake on 5 August 2005, Wenshan $M_{\mathrm{S}} 5.3$ earthquake on 13 August 2005 occurred in the obvious water level step-like rising areas of Yunnan province. Based on above cases, it can be concluded that the obvious water level step-like rising effect area should be the areas where earthquakes will occur, which is not only for Fujian region.

\section{Discussion and conclusions}

The water levels of Fujian subsurface fluid network are sensitive to distant earthquakes, so a lot of them showed coseismic response to global earthquakes of $M \geq 8.0$. The coseismic responds observed in Fujian province are various, including the step-like rising/declining and water level oscillation. Their coseismic responses may change with space and time. The water level step-like rising was observed in the area of tectonic compressive region and the step-like declining was observed in the tensional region. The areas of obvious water level step-like rising should be the areas of obvious tectonic compression and are more risky areas of earthquake occurrence in future.

As the interference from instruments and circumstance brings about difficulties for effective earthquake prediction, the water level step-like rising caused by distant earthquake should be a useful supplement for earthquake prediction. If the obvious water level step-rising observed concentrates in one area after a large earthquake, the area needs to be monitored more tightly because large earthquakes maybe occur there.

Based on the earthquake cases, the numerous water level step-like rising sites may indicate the short time span before a future earthquake.

As data of a few cases is available, the above conclusion should be tested further with more earthquake cases.

Acknowledgements This paper is supported jointly by the project from China Earthquake Administration, the Chinese National Science and Technology Program (2006BAC01B02-03-02) and the foundation from Administration Earthquake of Fujian province (200801).

\section{References}

Cai Z H (1980). Introduction to Seismic Fluid Geosciences. Seismological Press, Beijing, 171-173 (in Chinese with English abstract).

Che Y T (1990). Studies on the conditions affecting the sensitivity of observational well related to earthquake precursors. Earthquake Research in China 6(4): 67-73 (in Chinese with English abstract).

Che Y T, Wang T C and Yu J Z (1989). Actuality and pulse of water level oscillation research in China. Earthquake 9(1): 70-72 (in Chinese with English abstract).

Che Y T and Yu J Z (1992). Test and observational studies of the earthquake-corresponding mechanism of groundwater behaviors. J Seis Res 15(2): 171-179 (in Chinese with English abstract).

Chen D Q and Liu Y W (2006). Summaries of the research of the co-seismic response of well-aquifer systems to seismic waves in China. Recent Developments in World Seismology (7): 27-31 (in Chinese with English abstract).

Department of Monitoring and Prediction, China Earthquake Administration (2005). 2004 Indonesia 8.7 Sumatra Earthquake and its Impact on the Chinese Mainland Region. Seismological Press, Beijing, 131-285 (in Chinese).

Editorial Board of Tangshan Earthquake in 1976, State Seismological Bureau (1982). Tangshan Earthquake in 1976. Seismological Press, Beijing, 444-445 (in Chinese).

Gao X Q, Chen H J, Yang Y L, Li Z H and Xu Q L (2006). Coseismal effect of Indonesia M8.7 earthquake on Dec. 26, 2004 in Xinjiang region. Seismological and Geomagnetic Observation and Research 27(3): 40-45 (in Chinese with English abstract).

Huang F Q, Chi G C, Xu G M, Jian C L and Deng Z H (2000). Research on the response anomalies of subsurface fluid in mainland monitoring network to the Nantou earthquake with $M_{\mathrm{S}}$ 7.6. Earthquake 20(S1): 119-125 (in Chinese with English abstract).

Fu H, Liu Q, Wu C D, Wang Y A and Wu X P (2007). Small earthquakes triggered by the Indonesia $M 8.7$ and $M 8.5$ earthquakes and the fluid anomaly response in Yunnan, China. J Seis Res 30(1): 7-13 (in Chinese with English abstract).

Liao L X, Fu H, and Yang X H (2006). Study on tectonic dominator from after-seismic character of the ground fluid after Indonesia M8.7 earthquake and its hint to the subsequent. In: The Collection of Paper Abstracts of the Sixth International Symposium on Tianshan Earthquakes. Ürümqi, China, September 2006, 191-192 (in Chinese with English abstract).

Liao L X and Wang M L (2008). The characteristic analysis of response to the $M 8$ large earthquake of Indonesia of water level network of Fujian Province. Seismological and Geomagnetic Observation and Research 29(4): 67-72 (in Chinese with English abstract).

Wan D B (1992). Recording capacity variation of water level in wells and its relation to large earthquakes. J Seism Res 15(4): 381-391 (in Chinese with English abstract).

Wang C M, Che Y T and Wan D K (1998). Study of Micro-seismic Groundwater. Seismological Press, Beijing, 10-46 (in Chinese).

Zhang Z D, Zhao S P and Dong C F (1994). Quantitative relationship between the step variation in well water level and the bulk stress in the aquifer. Chinese J Geophys 37(S1): 222-229 (in Chinese with English abstract).

Zhang Z D, Chi Z L, Chen H M and Luan G Y (1999a). The transmissibility coefficient of well aquifer and its response to seismic wave. Inland Earthquake 13(3): 207-214 (in Chinese with English abstract).

Zhang Z D, Chi Z L, Chen H M and Luan G Y (1999b). Test of frequency characteristic for well and its response to seismic waves. Acta Seismologica Sinica 12(3): 365-367.

Zhang Z D, Chi Z L, Chen H M and Luan G Y (2000). Vibration of water level in well and earthquake wave. $J$ Seis Res 23(4): 418-425 (in Chinese with English abstract). 